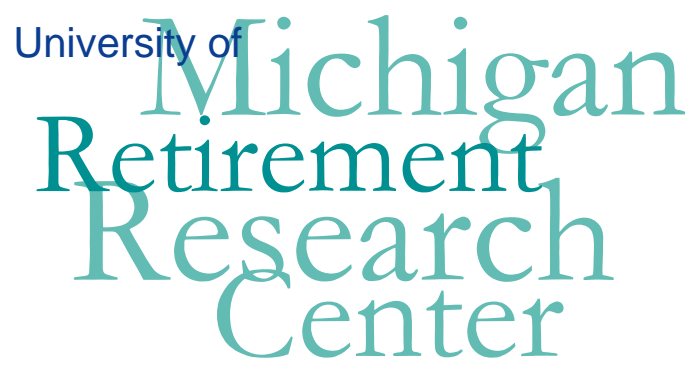

Working Paper WP 2006-138

\title{
Retirement Savings Portfolio Management
} Jeff Dominitz and Angela A. Hung

\begin{tabular}{|l|l|}
\hline $\mathrm{M}$ & $\mathrm{R}$ \\
\hline $\mathrm{R}$ & $\mathrm{C}$ \\
\hline
\end{tabular}$\quad$ Project \#: UM06-20 


\title{
“Retirement Savings Portfolio Management”
}

\author{
Jeff Dominitz \\ RAND
}

Angela A. Hung

RAND

October 2006

\author{
Michigan Retirement Research Center \\ University of Michigan \\ P.O. Box 1248 \\ Ann Arbor, MI 48104 \\ http://www.mrrc.isr.umich.edu/ \\ (734) 615-0422
}

\section{Acknowledgements}

This work was supported by a grant from the Social Security Administration through the Michigan Retirement Research Center (Grant \# 10-P-98358-5). The findings and conclusions expressed are solely those of the author and do not represent the views of the Social Security Administration, any agency of the Federal government, or the Michigan Retirement Research Center.

\section{Regents of the University of Michigan}

David A. Brandon, Ann Arbor; Laurence B. Deitch, Bingham Farms; Olivia P. Maynard, Goodrich; Rebecca McGowan, Ann Arbor; Andrea Fischer Newman, Ann Arbor; Andrew C. Richner, Grosse Pointe Park; S. Martin Taylor, Gross Pointe Farms; Katherine E. White, Ann Arbor; Mary Sue Coleman, ex officio 


\title{
Retirement Savings Portfolio Management
}

\author{
Jeff Dominitz and Angela A. Hung
}

\begin{abstract}
We assess the welfare implications of alternative retirement plan investment options given that households may not invest according to optimal portfolio choice theory but may instead use simple decision rules. We simulate the performance of lifestyle, lifecycle, and other simple strategies for allocating retirement savings. We find that if investors use simple rules of thumb to choose investments, then the impact of these strategies on welfare depend to a large extent on the choice set they are offered. If larger choice sets cause them to undertake more risk, then risk tolerant individuals may tend to be made better off. If larger choice sets cause them to reduce suboptimally low levels of portfolio risk, then the increased choice set may make them substantially worse off. The welfare effects of plan designs that induce lifecycle investing, which tends to be conservative over the lifetime, therefore depend crucially on the counterfactual portfolio composition, as well as preferences and non-retirement wealth.
\end{abstract}




\section{Introduction}

Standard investment advice calls for individuals to reduce the allocation to risky assets with age, or, more precisely, as the investment horizon shortens. Canner et al. (1997), for example, cite a rule of thumb stock allocation percentage of 100 minus age. More generally, so-called lifecycle funds decrease the share in equities as the investor ages. These funds have become increasingly popular investment vehicles in the United States. In fact, President Bush's recent proposal to reform Social Security, entitled Strengthening Social Security in the 21st Century, called for allocating the entire investment portfolio at age 47 to a lifecycle fund, subject to an opt-out provision.

Yet, the increasing popularity of lifecycle funds and associated investment strategies runs counter to a key finding by Samuelson (1969) that the portfolio allocation should be invariant to the investment horizon. Samuelson (1994) discusses several exceptions to this result, as do Jagannathan and Kocherlakota (1996) and Ameriks and Zeldes (2004). For example, one must account for human capital wealth when assessing the allocation of total wealth, in which case age variation of the optimal financial wealth allocation depends crucially on the variation of labor market earnings with financial market returns. The possibility for a labor supply response to financial market realizations as a form of hedging offers a clearer justification for a lifecycle investment strategy (Bodie, Merton, and Samuelson, 1992). Standard investment advice, however, tends to ignore these aspects of prospective labor market earnings, focusing instead on risk tolerance, investment horizon, and, perhaps, the extent of background risks, 
such as labor income risk.

In their review of theoretical justifications for lifecycle investment strategies, Ameriks and Zeldes (2004) note the possibility that risk preferences vary systematically with age. If investors become more risk averse with age, then the optimal portfolio allocation will become more conservative as the investor ages. A similar argument holds for their expectations. That is, if expectations of returns to risky assets become lower with age, as has been found by Dominitz and Manski (2004, 2006), then the optimal portfolio allocation of a risk averse investor will become more conservative as the investor ages. Dominitz and Manski also find that expectations tend to follow lagged stock market outcomes. If households make portfolio choices based on such beliefs, then we would expect to find that they "chase returns," which would lead to particularly bad outcomes in a world with negative serial correlation of returns.

Recent work in behavioral finance suggests that, whatever their preferences, expectations, and background risks, investors do not make optimal portfolio allocation decisions. Instead, they tend to use heuristics or simple decision rules to make their initial allocation decisions. Madrian and Shea (2001) examine 401(k) allocation behavior by a group of employees from a Fortune 500 company and find that an individual's allocation of regular contributions to a 401(k) plan is sensitive to enrollment default options. One group of employees in their analysis are automatically enrolled in the 401(k) plan unless they explicitly choose to opt out. For these employees, the default investment for the $401(\mathrm{k})$ plan is a money market fund. The authors find that over $90 \%$ of these employees hold the money market fund in 
their $401(\mathrm{k})$ balance, and $75 \%$ of these employees hold their entire $401(\mathrm{k})$ balance in the money market fund. In contrast, of employees from this same company for whom there is no default fund allocation, less than $20 \%$ hold any money market fund in the their $401(\mathrm{k})$ balance.

A related example of apparently suboptimal decision making is the preponderance of the " $\frac{1}{n}$ rule" documented by Benartzi and Thaler (2001). These authors find that investor allocation decisions are heavily dependent upon the choices offered to them. Roughly speaking, if they are offered $n$ choices, then they tend to allocate $\frac{1}{n}$ of their investment to each of the choices offered, independently of the risk characteristics of the investment opportunities. This decision rule implies that participants in a plan that offers numerous equity funds and few bond funds will end up allocating most of their savings to equity funds, regardless of individual risk preferences and investment horizons.

By analyzing financial records provided by Vanguard for over 570,000 participants in 639 defined contribution plans, Huberman and Jiang (2006) find that investors follow the $\frac{1}{n}$ rule, but the " $n$ " used in the denominator is not the number of fund choices available. Instead, they find that most investors equally allocate their $401(\mathrm{k})$ contributions across a subset of funds. This subset is typically composed of less than four funds, and the number of chosen funds is independent of the size of the choice menu. Furthermore, in contrast to Benartzi and Thaler's finding, Huberman and Jiang find only a marginal relation between participant equity allocation and the proportion of equity funds offered in their 401(k) plan. 
In contrast, Iyengar and Jiang (2005) find that in the presence of additional choices, investors choose less risky options. The implication of their finding is that participants in a plan that offers numerous equity funds and few bond funds will allocate more savings to bond funds than if there were fewer equity funds offered.

Retirement portfolios are rarely adjusted. The overwhelming majority of individuals engage in no rebalancing of 401(k) portfolios in any year (Hewitt Associates, 2004; Investment Company Institute, 2001; Samuelson and Zeckhauser, 1988). Even where the introduction of Internet access was found to greatly increase trading activity, most participants were inactive over a three-year period of study that immediately preceded the stock market collapse of 2000 (Choi et al, 2002). One may attribute the lack of portfolio rebalancing to a deliberate buy-and-hold strategy. Yet such a strategy may be suboptimal when equities exhibit wide swings in value over time, such as during the past decade. A very different conclusion about transactions was reached by Odean (1999), who asked whether investors trade too much. His sample, however, consisted of individuals who had brokerage accounts, whose active behavior in these accounts seems to differ greatly from the inactivity observed in retirement accounts.

Our goal here is to assess the welfare implications of alternative retirement plan investment options given that households may not invest according to optimal portfolio choice theory but may instead use simple decision rules. It is these decision rules that have led to calls for the use of lifecycle funds as the default investment choice. But would investment in a single lifecycle fund be better for all such households, who have heterogeneous preferences 
and wealth? If so, then, in the context of a personal retirement account component of Social Security, why not just have an independent agency invest the funds for everyone, perhaps with an opt-out provision along the lines proposed by President Bush for age- 47 and above?

We address such questions by performing numerous simulations based on the historical distribution of returns to common stock, long-term government bonds, and Treasury bills, as used by Canner et al. (1997). We also add simulated funds designed to mimic the choice set facing participants in the federal government employee Thrift Savings Plan (TSP), one of which is a lifecycle fund. Finally, we add three so-called lifestyle funds. The final report of the President's Commission to Strengthen Social Security (2001) recommended offering three such balanced funds-"conservative, medium, and growth." We implement these funds as mixes of the other funds. Our lifecycle fund is also a mix of the other funds, with the fraction in risky assets declining linearly as retirement approaches.

The approach we take to addressing these questions is similar in spirit to Calvet et al. (2006). They assess the welfare costs of household investment "mistakes" in Sweden, focusing on under-diversification of risky assets and nonparticipation in risky asset markets. The finding that households who do participate are insufficiently diversified suggest that the costs of nonparticipation are smaller than they would be otherwise. Thus, these authors recognize that the expected benefits of participation must be assessed based on some notion of how households will actually behave once they choose to participate.

The work of Poterba et al. (2006) is also particularly relevant. Using simulations based on 
historical returns in the United States, they assess the outcomes of a number of investment strategies, including (1) 100\% investment in inflation indexed long-term bonds, corporate stock, or long-term government bonds, (2) lifecycle funds, (3) the "No Lose" strategy proposed by Feldstein (2005), and (4) simulated "optimal strategies." They find that the welfare implications of the various strategies are very sensitive to assumptions on preferences, wealth held outside of retirement plans, assets returns, and expense ratios. The role of expense ratios is particularly relevant when one considers the benefits of lifecycle funds, which tend to carry higher ratios.

The paper is organized as follows. In Section 2 we present theoretical models of portfolio choice. We take a textbook model of dynamic decision making under uncertainty and then adapt it to the case of retirement portfolio choice. With preferences exhibiting constant relative risk aversion (CRRA), it has been shown that a household optimally holds a constant share of risky assets. We show that if preferences instead exhibit constant absolute risk aversion (CARA), then the share declines with age, as prescribed by advocates of lifecycle investment strategies. Of course, households almost certainly have neither CARA nor CRRA preferences, but it is worthwhile to learn how sensitive the optimal portfolio is to variation in the specification of preferences.

Section 3 describes the specifications for the simulations, the results of which are discussed in Section 4. We find that, over the lifetime, aggressive investing outperforms other lifestyle strategies, as well as lifecycle investing and simple heuristics, when investors can tolerate 
variability of returns either because they have a low coefficient of relative risk aversion or they have considerable wealth held outside of the retirement account. Should investors use simple rules of thumb to choose investments, then the impacts of these strategies on welfare depend largely on the choice set. If larger choice sets cause them to undertake more risk, then risk tolerant individuals tend to be made better off. If larger choice sets cause them instead to reduce risks, then the increased choice set may make many worse off. In the latter case, plan designs that induce lifecycle investing may be desired. Section 5 concludes.

\section{Models of Portfolio Choice}

\subsection{Basic Model of Portfolio Choice}

Following Blanchard \& Fischer (1989, Chapter 6.2), we consider a consumer who lives until period $T$. In any period $t$, the consumer chooses consumption $C_{t}$ to maximize

$$
E\left[\sum_{s=t}^{T} \beta^{s-t} U\left(C_{t}\right) \mid \Phi_{t}\right]
$$

where $\Phi_{t}$ denotes the period- $t$ information set and future utility $U\left(C_{t+j}\right)(j>0)$ is discounted by $\beta^{j}$.

To begin, let the consumer be uncertain about future income $Y_{t+j}(j>0)$. The consumer can allocate current period savings $Y_{t}-C_{t}$, as well as accumulated assets $A_{t}$, between a riskless asset yielding a known rate of return $r_{t}$ and a risky asset yielding an uncertain rate 
of return $z_{t}$. Let the fraction $\omega_{t}$ denote the share of the portfolio allocated to the riskless asset. The budget constraint is given by

$$
\begin{aligned}
A_{t+1} & =\left(A_{t}+Y_{t}-C_{t}\right)\left[\left(1+r_{t}\right) \omega_{t}+\left(1+z_{t}\right)\left(1-\omega_{t}\right)\right] \\
A_{t} & \geq 0
\end{aligned}
$$

The consumer chooses a consumption and portfolio plan at time 1, knowing that he will be able to choose a new plan at time 2 , and then again at time 3 , and each period thereafter. To solve for first-period consumption $C_{1}$ and portfolio share $\omega_{1}$, we may use stochastic dynamic programming. We first define the value function

$$
V_{t}\left(A_{t}\right)=\max E\left[\sum_{s=t}^{T} \beta^{s-t} U\left(C_{s}\right) \mid \Phi_{t}\right] \text { subject to the budget constraint }
$$

The value function satisfies the Bellman equation

$$
V_{t}\left(A_{t}\right)=\max _{\left\{C_{t}, \omega_{t}\right\}} U\left(C_{t}\right)+\beta E\left[V_{t+1}\left(A_{t+1}\right) \mid \Phi_{t}\right]
$$

With fully diversifiable income $Y_{t}$, explicit solutions can be derived for the hyperbolic absolute risk aversion class of utility functions, which include constant relative risk aversion, constant absolute risk aversion, and quadratic utility functions. Under specifications of utility and beliefs on income and returns, we can solve for the optimal consumption and portfolio plan 
via backward induction.

\subsection{A Basic Model of Retirement Portfolio Choice}

We now introduce a second form of wealth accumulation in the form of retirement assets $M_{t}$.

Let $m_{t}$ denote the amount of the period- $t$ contribution to retirement savings, to be allocated between the riskless asset and the risky asset. Retirement assets accumulate according to

$$
\begin{aligned}
M_{t+1} & =\left(M_{t}+m_{t}\right)\left[\left(1+r_{t}\right) \alpha_{t}+\left(1+z_{t}\right)\left(1-\alpha_{t}\right)\right] \\
M_{t} & \geq 0
\end{aligned}
$$

where $\alpha_{t}$ is the period- $t$ allocation of retirement assets to the riskless asset. To describe the evolution of assets held outside of the retirement account, we may modify the earlier budget constraint as follows

$$
\begin{aligned}
A_{t+1} & =\left(A_{t}+Y_{t}-C_{t}-m_{t}\right)\left[\left(1+r_{t}\right) \omega_{t}+\left(1+z_{t}\right)\left(1-\omega_{t}\right)\right] \\
A_{t} & \geq 0
\end{aligned}
$$

If there were no restrictions on retirement savings accounts and no tax benefits, as is the case here, then the consumer is indifferent between putting a dollar into retirement savings or into regular savings. Further, any tax benefits yielding a higher effective rate of return on return retirement savings would cause the consumer to hold all wealth in the retirement account. 
The combination of restrictions on and tax-preferred treatment of retirement accounts yields optimal portfolio choices that are more complicated. See, for example, Dammon, Spatt, and Zhang (2004).

To simplify the problem, we begin by placing extreme restrictions on pre-retirement income and savings. First, we assume that retirement is known with certainty to take place in period $\tau<T$. For all periods $t<\tau$, the periodic contribution to retirement assets is fixed at $m_{t}=m$. In period $\tau$, the consumer must dissolve the retirement account and purchase an annuity, a requirement that has been included among proposals for private investment of Social Security. Therefore, no further contributions are made; that is, $m_{t}=0$ for all $t \geq \tau$. Further, we will assume that the only form of retirement income is the annuity income $Y_{t}^{A}$, which is assumed to be fixed across time and is determine solely by the period- $\tau$ level of retirement assets $M_{\tau}$ according to an annuity income function $Y_{t}^{A}\left(M_{\tau}\right)$.

With these restrictions, we see that the budget constraint in retirement $t \geq \tau$ reverts to the familiar form

$$
\begin{aligned}
A_{t+1} & =\left(A_{t}+Y_{t}^{A}\left(M_{\tau}\right)-C_{t}\right)\left[\left(1+r_{t}\right) \omega_{t}+\left(1+z_{t}\right)\left(1-\omega_{t}\right)\right] \\
A_{t} & \geq 0
\end{aligned}
$$


As before, we may write the Bellman equation as

$$
V_{t}\left(A_{t}\right)=\max _{\left\{C_{t}, \omega_{t}\right\}} U\left(C_{t}\right)+\beta E\left[V_{t+1}\left(A_{t+1}\right) \mid \Phi_{t}\right] \quad \text { for any } t \geq \tau
$$

because, at time $\tau$, the future evolution of retirement assets is fully determined.

In any period $t<\tau$, the consumer must choose $C_{t}, \omega_{t}$, and $\alpha_{t}$ to maximize expected utility, subject to the constraints

$$
\begin{aligned}
M_{t+1} & =\left(M_{t}+m\right)\left[\left(1+r_{t}\right) \alpha_{t}+\left(1+z_{t}\right)\left(1-\alpha_{t}\right)\right] \\
M_{t} & \geq 0
\end{aligned}
$$

and

$$
\begin{aligned}
A_{t+1} & =\left(A_{t}+Y_{t}-C_{t}-m\right)\left[\left(1+r_{t}\right) \omega_{t}+\left(1+z_{t}\right)\left(1-\omega_{t}\right)\right] \\
A_{t} & \geq 0
\end{aligned}
$$

The Bellman equation may be written as

$$
V_{t}\left(A_{t}, M_{t}\right)=\max _{\left\{C_{t}, \omega_{t}, \alpha_{t}\right\}} U\left(C_{t}\right)+\beta E\left[V_{t+1}\left(A_{t+1}, M_{t+1}\right) \mid \Phi_{t}\right] \quad \text { for any } t<\tau
$$


Note that we now have two state variables, $A_{t}$ and $M_{t}$, until $t=\tau$. In period $\tau$, the dependence of the value function on $M_{t}$ ends because the consumer must dissolve the retirement holdings. We may therefore write $V_{t}\left(A_{t}\right)$ in place of $V_{t}\left(A_{t}, M_{t}\right)$ for all $t \geq \tau$. Before simplifying the model further, we note that the existence of both retirement and non-retirement portfolios complicates any analysis of retirement portfolios alone. We now abstract from these concerns to focus on the central issue of retirement portfolio management.

Suppose that wealth can only be accumulated in the form of retirement assets, as modelled above. Thus, we now have just one state variable $M_{t}$, which evolves according to

$$
\begin{aligned}
M_{t+1} & =\left(M_{t}+m\right)\left[\left(1+r_{t}\right) \alpha_{t}+\left(1+z_{t}\right)\left(1-\alpha_{t}\right)\right] \\
M_{t} & \geq 0
\end{aligned}
$$

for all $t<\tau$. In period $\tau$, the consumer must dissolve the retirement account and purchase an annuity. Income from this annuity $Y_{t}^{A}, t \geq \tau$, will simply be spent on consumption. That is,

$$
U\left(C_{t}\right)=U\left(Y_{t}^{A}\right) \text { for all } t \geq \tau
$$

and we assume assume $Y_{t}^{A}\left(M_{\tau}\right)=\frac{M_{\tau}}{T-\tau} \forall t \geq \tau$. Prior to retirement, all income is spent on consumption, but for the fixed contribution to the retirement account; therefore,

$$
U\left(C_{t}\right)=U\left(Y_{t}-m\right) \text { for all } t<\tau
$$


Thus, the only choice variable is the retirement asset portfolio share $\alpha_{t .}$.

Suppose utility reflects CARA preferences:

$$
U(c)=1-e^{-\gamma c}
$$

where $\gamma>0$ is the coefficient of absolute risk aversion. Furthermore, assume that rate of return on the risky asset is normally distributed with mean $\mu$ and variance $\sigma^{2}$.

Given these assumptions, the optimal retirement asset portfolio share at $j$ periods before retirement is:

$$
\alpha_{\tau-j}^{*}=1-\frac{\mu-r_{\tau-j}}{\sigma^{2} \gamma\left(m+M_{\tau-j}\right) \prod_{n=1}^{j-1}\left(r_{\tau-n}+1\right)}
$$

As long as the expected returns to the risky asset exceed the riskless rate, $\alpha_{t}$ tends to increase in (a) the degree of risk aversion and (b) the riskiness of the risky asset. Further, the optimal portfolio share $\alpha_{t}$ will tend to increase over time as retirement approaches, as is the case with lifecycle funds. 


\section{Simulation Specifications}

\subsection{Retirement Savings Contributions}

We develop a tractable approach to the simulations by considering only the contributions to the retirement savings account. Mirroring the approach taken in Poterba et al. (2006), we make our welfare calculations of utility of total wealth held at retirement in period $\tau$ by combining the two forms of wealth. Our simulations will include a range of values for non-retirement wealth holdings to assess the sensitivity of the results to assumptions on these holdings. Poterba et al. find that the welfare implications of alternative investment strategies are very sensitive to these assumptions.

To simulate retirement account contributions, we consider three types of households with one worker whose earnings profile is based on level of education-less than high school, some college, and college degree-simulated based on previous empirical findings (Heckman et al., 2003; and Hubbard et al., 1995). In particular, we use point estimates in Heckman et al. (2003) to determine mean log earnings as follows:

$$
\left.6.8912+(.1292 E)+(.1301 X)-\left(.0023 X^{2}\right)\right)
$$

where $E$ is years of schooling (11 for less than high school, 14 for those with some college and 16 for college graduates) and $X$ is years of experience and calculated as $(a g e+18-E)$. Log earnings are assumed to follow an $\mathrm{AR}(1)$ process with autocorrelation coefficient $\rho$ and a 
mean zero innovation that is normally distributed with standard deviation $\sigma$. From Hubbard et al. (1995), we specify:

\begin{tabular}{|lll|}
\hline education level & $\sigma$ & $\pi$ \\
\hline \hline less than high school & 0.033 & 0.955 \\
some college & 0.025 & 0.946 \\
college & 0.016 & 0.955 \\
\hline
\end{tabular}

We consider households who contribute 9 percent of pretax earnings to the retirement account, as in the Poterba et al. simulations, as well as households who contribute only 5 percent.

Following Porterba et al. (2006), we assume that households have preferences that exhibit CRRA. We consider three levels of risk aversion: mild risk aversion $(\gamma=1.1)$, moderate risk aversion $(\gamma=2)$, and strong risk aversion $(\gamma=5)$

\subsection{Investment Choice Sets}

We begin with a baseline set of 3 funds: F1 composed solely of Treasury bills, F2 composed solely of long-term government bonds, and F3 composed solely of common stock. We also simulate the effects of adding consider two additional equity funds, F4 and F5, just as the TSP added a small-cap (S) fund and an international (I) fund in 2001 to the three previously available funds-the short-term nonmarketable Treasury securities (G) fund, the bond index (F) fund, and the equity index (C) fund. 
We also simulate the effects of adding funds that are created by blending the other funds. We add a lifecycle fund (LF), just as the TSP added a lifecycle (L) fund in 2005. We also add three lifestyle funds-B1 (conservative), B2 (moderate), and B3 (aggressive). Thus, the largest choice set includes nine funds, but four of these are linear combinations of the other five.

The conservative lifestyle fund holds 40 percent in Treasury bills and 15 percent each in funds F2-F5. The moderate lifestyle fund allocates equally across all five funds. The aggressive lifestyle fund holds no treasury bills and 25 percent each in F2-F5. In each case, the ratio of stocks to bonds is 3-to-1, equal to the Canner et al. (1997) calculation of the optimal ratio based on historical returns from 1926 to 1992 which also form the foundation for our specification of stochastic returns as describe below. The selected allocations to T-bills are calibrated based on holdings in lifestyle funds reported by Canner et al.

The lifecycle fund is implemented in line with the simple heuristic cited by Canner et al. The proportion in F1 is linearly increasing in age while maintaining fixed ratios among F2 F5. In particular, the initial allocation for the lifecycle fund places nothing in Treasury bills and 25 percent each in the remaining funds. Each subsequent year, one percent from each of the funds, F2-F5 is shifted to Treasury bills. Therefore, the lifecycle fund initially mimics the aggressive lifestyle fund. At 45 years of age, the lifecycle fund mimics the moderate lifestyle fund and at 65 years of age the lifecycle fund mimics the conservative lifestyle fund. As such, the fund maintains a 3 -to-1 ratio of stocks to bonds 


\subsection{Stochastic Returns}

Canner et al. (1997) report descriptive statistics for the historical distribution of annual real returns from 1926-1992 for Treasury Bills, long-term government bonds, and common stock, which we use to determine the stochastic returns to F1, F2, and F3. We add two stylized equity funds-F4 and F5-to our simulations. 


$\begin{array}{lll} & \text { Arithmetic } & \text { Standard } \\ \text { Asset } & \text { mean return } & \text { Deviation }\end{array}$

$(\%) \quad(\%)$

$\begin{array}{lll}\text { Treasury } & 0.6 & 4.3 \\ \text { Bills (F1) } & & \end{array}$

$\begin{array}{lll}\text { Long-Term } & 2.1 & 10.1 \\ \text { Government } & & \end{array}$

Bonds (F2)

$\begin{array}{lll}\text { Common } & 9.0 & 20.8\end{array}$

Stock (F3)

Stylized

$10.0 \quad 23.0$

Equity

Fund (F4)

Stylized

$10.0 \quad 23.0$

Equity

Fund (F5) 


$\begin{array}{ccccc} & \text { Correlation } & \text { Correlation } & \text { Correlation } & \text { Correlation } \\ \text { Asset } & \text { with } & \text { with } & \text { with } & \text { with }\end{array}$

Bonds (F2) Stocks (F3) Stocks (F4) Stocks (F5)

Treasury

0.63

0.09

0.10

0.10

Bills (F1)

Long-Term

1.00

0.23

0.20

0.20

Government

Bonds (F2)

Common

0.23

1.00

0.60

0.60

Stock (F3)

\section{Stylized}

0.20

0.60

1.00

0.60

Equity

Stock (F4)

Stylized

0.20

0.60

0.60

1.00

Equity

Fund (F5) 
We generate the returns to the three baseline line funds (F1, F2, and, F3) from a multivariate normal distribution of returns characterized by the above means, standard deviations, and correlations. The additional stock funds (F4 and F5) are generated with higher means and variances than the common stock fund, exhibiting strong positive correlation with each other and with the common stock fund F3. Together, the joint distribution of the returns to the five funds are multivariate normal.

\subsection{Investment Strategies}

We consider three types of strategies-lifecycle investing, lifestyle investing, and simple heuristics. The lifecycle strategy mirrors the lifecycle fund in the investment choice set.

We label as lifestyle strategies an approach that follows from the findings on optimal portfolio choice by Samuelson (1969) and others and simply keeps a fixed portfolio allocation across periods until retirement. Note that with CRRA preferences and normally distributed returns, this approach should be optimal. However, rather than letting each individual choose the optimal allocation given preferences, we simulate only three allocations, mirroring the conservative, medium, and growth funds in the choice set. Thus, the behavior of an individual

choosing, for example, the conservative lifestyle strategy is invariant to the expansion of the choice set from five to nine funds. When the choice set consists just of three funds-F1, F2, and F3-each lifestyle strategy allocation to F1 and F2 remains unchanged, whereas the allocation to F3 is tripled, thereby maintaining the 3-to-1 ratio of stocks to bonds. 
Finally, we simulate two strategies based the heuristics identified in the behavioral finance literature. The $\frac{1}{n}$ decision rule is very simple to implement for retirement contributions. Clearly, this strategy is sensitive to every change in choice set. We also consider a "sure bet" decision rule based on the findings of Iyengar and Jiang (2005), whereby an expansion of the choice set leads to an increased allocation to the safest fund, F1. With the three baseline funds, we use the $\frac{1}{n}$ rule. Then, as the choice set expands, an increasing fraction is allocated to the F1 fund and the remainder is allocated equally across the other funds, as in Huberman and Jiang (2006). In particular, when the choice set includes five funds, the "sure bet" decision rule allocates 40 percent to T-bills and 15 percent each to the remaining

funds. Note that this allocation is identical to the conservative lifestyle fund, B1. When the choice set includes nine funds, the "sure bet" decision rule allocates 60 percent to treasury bills and 5 percent each to the remaining funds.

\section{Results}

\subsection{Wealth Accumulation}

Figure 1A describes the simulation results for an individual with 11 years of education (i.e., less than high school diploma) who contributes $5 \%$ of earnings to a retirement account for 40 years, starting at age 25 . For each investment strategy and choice set, we perform 10,000 simulations of total retirement wealth accumulation. The boxes in Figure 1A depict the 
central tendency of the distribution of simulated wealth accumulation, where the top of the box is the mean and the bottom of the box is the median. The mean always exceeds the median because the distribution of cumulative returns is positively skewed, whereas yearly returns are symmetric. The vertical lines depict the range between the 0.05 -quantile and the 0.95-quantile of accumulated wealth.

Figures 1B and 1C describe the distributions of outcomes for an individual with (1B) 11 years of education and a $9 \%$ contribution rate and (1C) 16 years of education and a $5 \%$ contribution rate. Inspection of these figures reveal that the variation in education levels and contribution rates basically leads to re-scaling of the vertical axes (i.e., the magnitude of wealth accumulation). That is, the greater the education or contribution rate, the larger is the accumulation. We may therefore restrict attention to the first set of simulations described in Figure 1A to understand the impact of investment strategies and choice sets on retirement wealth accumulation.

Consider first the outcomes with just three investment choices - Treasury bills (F1), long-term government bonds (F2), and common stock (F3). The outcomes for the other strategies can be interpreted relative to the outcomes for the conservative, moderate, and aggressive strategies, each of which maintain a three-to-one ratio of stock to bonds, with the specific allocations determined by the share in T-bills. Not surprisingly, allocating less to T-bills (i.e., more aggressive investing) yields a greater central tendency and spread of the wealth distribution. More importantly, the greater expected returns are not associated 
with much, if any, increase in the probability of a low level of wealth accumulation. The 0.05 -quantile is around $\$ 50,000$ for each strategy, and is actually highest for the aggressive strategy.

By construction, the $\frac{1}{n}$-rule and the sure bet strategy yield identical outcomes with just three funds in the choice set. These strategies are very conservative, yielding lower wealth accumulation than the conservative strategy. Moreover, with a one-to-one ratio of stocks to bonds, these strategies basically miss out on the upper end up the distribution of returns to the conservative strategy without cutting off the lower end. Thus, the (.05-trimmed-) conservative distribution stochastically dominates the (0.05-trimmed-) distribution arising from the $\frac{1}{n}$ and sure bet strategies.

Recall that the lifecycle strategy begins with an allocation equal to that of the aggressive strategy, but reduces the allocation to risky assets until it equals the moderate allocation at age 45 and would mirror the conservative allocation at age 65 . We see that the accumulated wealth distribution looks more like a mix of conservative and moderate strategies alone. This outcome arises because aggressive investing occurs early on in the lifecycle, when wealth accumulation is relatively low, and conservative investing occurs later on when accumulated wealth is relatively large. Thus, this strategy is, effectively, a weighted average of the three lifestyle funds where the weights are determined by accumulated wealth. While conservative, this strategy seems to outperform the $\frac{1}{n}$ and sure bet strategies.

Now consider the outcomes with 5 choices-F1 to F5. The wealth distributions improve 
somewhat, in the sense of stochastic dominance, for each of the lifestyle strategies. This change arises mostly from the additional diversification, as the ratio of stocks to bonds and the allocation to T-bills is unchanged from the case of three choices.

We also see a substantial divergence in outcomes between the $\frac{1}{n}$ and the sure bet strategies. The addition of two equity funds causes the $\frac{1}{n}$ investor to allocate a greater share of total wealth to equities and reduce the allocation to either T-bills or bonds. In fact, this strategy now adopts the moderate investment strategy and, therefore, the 3-to- 1 ratio of stocks to bonds. The sure bet investor also uses the three-to-one ratio but increases the allocation to T-bills. Therefore, the $\frac{1}{n}$ strategy outperforms the sure bet strategy when faced with these five choices. Once again, the lifecycle investment strategy yields something in between conservative and moderate investing. As specified, it therefore generates higher expected returns than the sure bet strategy but not the $\frac{1}{n}$ rule.

Finally, consider the addition of four funds to yield nine choices. The performance of the three lifestyle strategies and the lifecycle strategy are unchanged, because they are simply mixes of the five other funds. The performance of the $\frac{1}{n}$ strategy is basically unchanged from the case of five choices, because mixing in the additional four funds does not have much effect on the resulting allocation to the original five funds. The central tendency of the accumulation based on the sure bet strategy falls markedly, however. This outcome arises from the increased allocation to T-bills, which also yields a substantial decrease in the spread of the distribution. 


\subsection{Certainty Equivalent Wealth Accumulation}

We evaluate the welfare implications of alternative investment strategies and choice sets by comparing certainty equivalent wealth (CEW) accumulations under CRRA preferences. We consider three values for the coefficient of relative risk aversion- $-1=1.1,2$, or 5 -and for the amount of wealth held at age 65 outside of the retirement account- $\$ 0 ; \$ 100,000$; or $\$ 250,000$. The results are presented in Table 1A and Table 1B. Figure 2A depicts the results for an individual with 11 years of education, a $5 \%$ contribution rate, and no wealth held outside of the retirement account. Figure 2B changes the outside wealth to $\$ 100,000$. These two figures capture much of the qualitative pattern of results described in Tables $1 \mathrm{~A}$ and $1 \mathrm{~B}$ for all the strategies, choice sets, education levels, and contribution rates.

With the greatest tolerance for risk $(\gamma=1.1)$, the pattern of variation in certainty equivalent wealth most closely resembles that for mean wealth presented in Figures 1A, 1B, and $1 \mathrm{C}$. Table 1B presents the findings for CEW for any strategy and choice set expressed as a fraction of the CEW under aggressive investment for the same choice set. With $\gamma=1.1$ or 2.0 and outside wealth of $\$ 0$ or $\$ 100,000$, the ratio always falls short of 0.90 . With outside wealth of $\$ 250,000$, the ratio sometimes exceeds 0.90 with $\gamma=2.0$ and $\$ 250,000$ in outside wealth and the moderate investment strategy, the $\frac{1}{n}$ rule, or lifecycle investing.

The most striking changes occur with no outside wealth and substantial risk aversion; that is, $\gamma=5.0$. Only in this case does moderate or conservative investing tend to outperform aggressive investing in terms of CEW. In fact, with just three assets in the choice set, the 
lifecycle strategy outperforms all others in these cases. With five or nine choices, the $\frac{1}{n}$ rule and lifecycle investing perform similarly, whereas the sure bet strategy lags far behind, especially when nine funds are available.

One main lesson seems to be that aggressive investing outperforms the other strategies when investors can tolerate variability of returns either because they have a low coefficient of relative risk aversion or they have considerable wealth held outside of the retirement account. Should investors use simple rules of thumb to choose investments, then the impact of these strategies on welfare depend to a large extent on the choice set they are offered. If larger

choice sets cause them to undertake more risk (e.g., $\frac{1}{n}$ rule and addition of equity funds), then risk tolerant individuals (e.g. low $\gamma$ and high outside wealth) will be made better off. If larger choice sets cause them to reduce risk (e.g., sure bet strategy), then the increased choice set may make many worse off. In the latter case, plan designs that induce lifecycle investing may be desired.

\section{Conclusions}

Throughout their working lives, individuals must choose how to allocate income between consumption and savings and how to allocate savings among numerous possible asset holdings, including those in dedicated retirement accounts. The evolution of these assets prior to and throughout the retirement years is an important determinant of financial security and well-being in old age. Yet individuals appear to make savings and investment decisions that 
are not easy to explain by conventional economic models. The growth of defined-contribution pension plans over the past two decades has increased the sensitivity of retirement security to variation in the returns to selected investments. Proposals for private accounts to replace or supplement Social Security benefits would strengthen this trend. This heightened sensitivity to financial market outcomes, together with findings that individuals tend to exhibit "behavioral anomalies" when it comes to financial decisions and to be poorly informed about their pension and Social Security benefits, raises concerns that an increasingly large portion of the population will reach normal or desired retirement age without adequate resources.

To address concerns about choices made in personal retirement accounts, President Bush's reform proposal called for automatic enrollment in a lifecycle fund at age- 47 , subject to an opt-out provision. But would investment in a single lifecycle fund be better for all such households, who must have heterogeneous preferences and wealth? If so, then, in the context of a personal retirement account component of Social Security, why not just have an independent agency invest the funds for everyone, perhaps with an opt-out provision?

The final report of the President's Commission to Strengthen Social Security (2001) offers the following argument against such a policy: "Personal accounts allow every investor to choose an investment portfolio that is consistent with his or her preferences, while central government investment essentially forces everyone into a 'one size fits all' portfolio" (page 38). Yet, given the apparent impact of default rules, is this not what the White House plan proposes to do? 
A full assessment of the merits of arguments about this issue require a better understanding of the welfare implications of deviations from optimal behavior. That is the goal of our simulations. We find a lifecycle investment strategy to be relatively conservative when taken from a lifetime perspective. That is, the most aggressive investing takes place early in life when retirement assets are relatively small, whereas investing gets progressively conservative as assets build. This strategy contradicts well known prescriptions from financial theory. We also find that this strategy may be outperformed by a simple $\frac{1}{n}$ rule. In contrast, while it does tend to be conservative, lifecycle investing may induce some investors to take on more risk than they would otherwise and to invest more efficiently than when left to their naive strategies.

\section{References}

[1] Ameriks, J., and S. Zeldes (2004). "How Do Household Portfolio Shares Vary With Age?" Working Paper.

[2] Barber, B., and T. Odean (2003), "Are Investors Tax Savvy? Asset Location Evidence from Retail and Discount Brokerage Accounts," Journal of Public Economics, 88, 419442.

[3] Benartzi, S., and R. Thaler (2001). "Naive Diversification Strategies in Defined Contribution Saving Plans," American Economic Review, 91, 79-98. 
[4] Blanchard, O., and S. Fisher (1989). Lectures on Macroeconomics, MIT Press.

[5] Bodie, Z., R. Merton, and P. Samuelson (1992). "Labor Supply Flexibility and Portfolio Choice in a Life Cycle Model," Journal of Economic Dynamics and Control, 16, 427-449.

[6] Calvet, L. E., J. Y. Campbell, P. Sodini, (2006). "Down or Out: The Welfare Implications of Household Investment Mistakes" NBER Working Paper No. 12030

[7] Canner, N., N. G. Mankiw, and D. Weil (1997). "An Asset Allocation Puzzle," American Economic Review, 87(1), 181-191.

[8] Choi, J., D. Laibson, and B. Madrian (2002). "How Does the Internet Affect Trading? Evidence from Investor Behavior in 401(k) Plans," Journal of Financial Economics, 64, pp. 397-421.

[9] Choi, J., D. Laibson, B. Madrian, and A. Metrick (2004). "For Better or For Worse: Default Effects and 401(k) Savings Behavior," in D. Wise, ed., Perspectives in the Economics of Aging, Chicago: University of Chicago Press.

[10] Dammon, R., C. Spatt, and H. Zhang (2004), "Optimal Asset Location and Allocation with Taxable and Tax-Deferred Investing," Journal of Finance, 59, 999-1037.

[11] Dominitz, J., and C. Manski (2004). "How Should We Measure Consumer Confidence?" Journal of Economic Perspectives, 18(2), 51-66. 
[12] Dominitz, J., and C. Manski (2006). "Expected Equity Returns and Portfolio Choice: Evidence from the Health and Retirement Study," presented in an invited session at the 2006 meetings of the European Economic Association, Vienna, Austria.

[13] Feldstein, M., (2005). "Reducing the Risk of Investment-Baed Social Security Reform," NBER working paper 11084.

[14] Hewitt Associates (2004). "Hewitt Study Shows Sluggish Interacting With 401(k) Plans: Research Shows Poor 401(k) Saving and Investing Habits Despite Improved Economy," press release dated May 24, 2004.

[15] Heckman, J. J., L. J., Lochner, and P. E. Todd (2003). "Fifty Years of Mincer Earnings Regressions," NBER working paper 9732.

[16] Hubbard, R. G., J. Skinner, and S. Zeldes (1995). "Precautionary Savings and Social Insurance," Journal of Polictical Economy,

[17] Huberman, G,. and W. Jiang (2006), "Offering vs. Choice in 401(k) Plans: Equity Exposure and Number of Funds," Journal of Finance, 16, 763-801

[18] Investment Company Institute (2001). "Redemption Activity of Mutual Fund Owners," Fundamentals: Investment Company Institute Research in Brief, Vol. 10, No. 1. 
[19] Investment Company Institute (2004). "Mutual Funds and the U.S. Retirement Market in 2003," Fundamentals: Investment Company Institute Research in Brief, Vol. 13, No. 2.

[20] Iyengar, S. S. and Jiang, W. "The Psychological Costs of Ever Increasing Choice: A Fallback to the Sure Bet" Columbia University Working Paper, 2005.

[21] Jagannathan, R., and N. Kocherlakota (1996). "Why Should Older People Invest Less in Stocks Than Younger People?" Federal Reserve Bank of Minneapolis Quarterly Review, 20(2) 11-23.

[22] Madrian, B., and D. Shea (2001). "The Power of Suggestion: Inertia in 401(k) Participation and Savings Behavior," Quarterly Journal of Economics, 116(4), pp. 1149-1187.

[23] Odean, T. (1999). "Do Investors Trade Too Much?" American Economic Review, 89(5), pp. 1279-1298.

[24] Poterba, J., J. Rauh, S. Venti, and D. Wise (2006). "Reducing Social Security Risk at the Individual Level - Lifecycle Funds and No-loss Strategies," Prepared from the 8th Annual Joint Conference of the Retirement Research Consortium, Washington, DC.

[25] President's Commission to Strengthen Social Security (2001). Strengthening Social Security and Creating Personal Wealth for All Americans: Report of the President's Commission, December 2001, available at www.csss.gov) 
[26] Samuelson, P. (1969). "Lifetime Portfolio Selection by Dynamic Stochastic Programming," Review of Economic Statistics, 51(3) 239-246.

[27] Samuelson, P. (1994). "The Long-Term Case for Equities: And how it can be oversold", Journal of Portfolio Management, 21(1) 15-24.

[28] Samuelson, W., and R. J. Zeckhauser (1988). "Status Quo Bias in Decision Making," Journal of Risk and Uncertainty, 1, 7-59. 
Table 1: Simulations of Certainty Equivalent Wealth Accumulation

Expressed in $\$ 1000$ s

11 Years of Education

\begin{tabular}{|c|c|c|c|c|c|c|c|c|c|c|c|c|c|c|c|c|c|c|c|}
\hline \multirow[b]{3}{*}{ Strategy } & \multirow[b]{3}{*}{ Choices } & \multicolumn{6}{|c|}{$\$ 0$ in Outside Wealth } & \multicolumn{6}{|c|}{$\$ 100 \mathrm{~K}$ in Outside Wealth } & \multicolumn{6}{|c|}{$\$ 250 \mathrm{~K}$ in Outside Wealth } \\
\hline & & \multicolumn{3}{|c|}{$5 \%$ Contribution Rate } & \multirow{2}{*}{\multicolumn{3}{|c|}{ 9\% Contribution Rate }} & \multicolumn{3}{|c|}{$5 \%$ Contribution Rate } & \multicolumn{3}{|c|}{ 9\% Contribution Rate } & \multirow{2}{*}{\multicolumn{3}{|c|}{$\begin{array}{c}5 \% \text { Contribution Rate } \\
\gamma=1.1\end{array}$}} & \multirow{2}{*}{\multicolumn{3}{|c|}{$\begin{array}{c}\text { 9\% Contribution Rate } \\
\gamma=1.1 \\
\gamma=2.0\end{array}$}} \\
\hline & & $\gamma=1.1$ & $\gamma=2.0$ & $y=5.0$ & & & & $y=1.1$ & $y=2.0$ & $\gamma=5.0$ & $\gamma=1.1$ & $y=2.0$ & $\gamma=5.0$ & & & & & & \\
\hline $1 / \mathrm{n}$ & 3 & 84.4 & 79.3 & 65.0 & 152.1 & 142.8 & 116.3 & 187.8 & 185.4 & 178.4 & 256.8 & 251.0 & 235.1 & 339.2 & 337.7 & 333.4 & 409.4 & 405.6 & 394.6 \\
\hline $1 / n$ & 5 & 141.1 & 123.9 & 81.5 & 251.1 & 221.8 & 149.5 & 250.4 & 240.0 & 214.5 & 362.1 & 341.0 & 290.5 & 405.5 & 398.3 & 379.7 & 520.1 & 504.2 & 464.9 \\
\hline $1 / n$ & 9 & 140.2 & 123.4 & 81.8 & 249.5 & 220.8 & 150.0 & 249.2 & 239.1 & 214.2 & 360.2 & 339.7 & 290.2 & 404.2 & 397.2 & 379.1 & 518.0 & 502.6 & 464.2 \\
\hline Sure Bet & 3 & 84.4 & 79.3 & 65.0 & 152.1 & 142.8 & 116.3 & 187.8 & 185.4 & 178.4 & 256.8 & 251.0 & 235.1 & 339.2 & 337.7 & 333.4 & 409.4 & 405.6 & 394.6 \\
\hline Sure Bet & 5 & 106.2 & 98.3 & 76.4 & 189.4 & 176.0 & 138.8 & 211.0 & 206.8 & 195.2 & 295.3 & 286.4 & 262.3 & 363.2 & 360.6 & 353.0 & 449.1 & 442.9 & 425.6 \\
\hline Sure Bet & 9 & 74.3 & 71.8 & 63.8 & 133.1 & 128.7 & 115.2 & 176.1 & 175.0 & 171.6 & 235.4 & 232.9 & 225.2 & 326.8 & 326.2 & 324.2 & 386.6 & 385.0 & 380.1 \\
\hline Conservative & 3 & 96.9 & 89.2 & 68.4 & 174.8 & 160.6 & 122.4 & 201.8 & 197.8 & 187.1 & 281.3 & 272.2 & 248.0 & 354.0 & 351.5 & 344.4 & 435.4 & 429.0 & 411.6 \\
\hline Conservative & 5 or 9 & 106.2 & 98.3 & 76.4 & 189.4 & 176.0 & 138.8 & 211.0 & 206.8 & 195.2 & 295.3 & 286.4 & 262.3 & 363.2 & 360.6 & 353.0 & 449.1 & 442.9 & 425.6 \\
\hline Moderate & 3 & 123.7 & 107.5 & 68.5 & 223.6 & 193.6 & 122.7 & 233.3 & 223.7 & 201.0 & 335.9 & 314.9 & 266.7 & 388.2 & 381.6 & 365.0 & 494.4 & 478.6 & 440.8 \\
\hline Moderate & 5 or 9 & 141.1 & 123.9 & 81.5 & 251.1 & 221.8 & 149.5 & 250.4 & 240.0 & 214.5 & 362.1 & 341.0 & 290.5 & 405.5 & 398.3 & 379.7 & 520.1 & 504.2 & 464.9 \\
\hline Aggressive & 3 & 155.5 & 124.8 & 62.7 & 281.5 & 225.0 & 112.6 & 271.8 & 251.9 & 211.8 & 402.0 & 360.0 & 278.6 & 431.4 & 416.5 & 384.1 & 567.5 & 534.0 & 465.0 \\
\hline Aggressive & 5 or 9 & 185.5 & 151.6 & 80.4 & 329.3 & 271.6 & 149.9 & 301.4 & 278.8 & 231.4 & 447.7 & 403.8 & 312.8 & 461.5 & 444.6 & 406.5 & 612.5 & 577.3 & 501.7 \\
\hline Life Cycle & 3 & 117.4 & 104.1 & 72.0 & 211.7 & 187.4 & 128.9 & 225.3 & 217.6 & 198.8 & 321.9 & 305.0 & 265.0 & 379.3 & 374.1 & 360.7 & 478.9 & 466.4 & 435.5 \\
\hline Life Cycle & 5 or 9 & 132.5 & 118.5 & 83.3 & 236.1 & 212.3 & 152.3 & 240.3 & 231.9 & 211.0 & 345.3 & 328.4 & 286.6 & 394.4 & 388.8 & 373.8 & 502.0 & 489.4 & 457.3 \\
\hline
\end{tabular}

14 Years of Education

\begin{tabular}{|c|c|c|c|c|c|c|c|c|c|c|c|c|c|c|c|c|c|c|c|}
\hline \multirow[b]{3}{*}{ Strategy } & \multirow[b]{3}{*}{ Choices } & \multicolumn{6}{|c|}{$\$ 0$ in Outside Wealth } & \multicolumn{6}{|c|}{$\$ 100 \mathrm{~K}$ in Outside Wealth } & \multicolumn{6}{|c|}{$\$ 250 \mathrm{~K}$ in Outside Wealth } \\
\hline & & \multicolumn{3}{|c|}{$5 \%$ Contribution Rate } & \multicolumn{3}{|c|}{ 9\% Contribution Rate } & \multicolumn{3}{|c|}{$5 \%$ Contribution Rate } & \multicolumn{3}{|c|}{ 9\% Contribution Rate } & \multicolumn{3}{|c|}{$5 \%$ Contribution Rate } & \multicolumn{3}{|c|}{ 9\% Contribution Rate } \\
\hline & & $\gamma=1.1$ & $\gamma=2.0$ & $y=5.0$ & $\gamma=1.1$ & $y=2.0$ & $y=5.0$ & $\gamma=1.1$ & $\gamma=2.0$ & $y=5.0$ & $\gamma=1.1$ & $\gamma=2.0$ & $y=5.0$ & $\gamma=1.1$ & $\gamma=2.0$ & $\gamma=5.0$ & $\gamma=1.1$ & $y=2.0$ & $\gamma=5.0$ \\
\hline $1 / \mathrm{n}$ & 3 & 116.0 & 109.6 & 90.9 & 209.3 & 197.8 & 164.7 & 219.6 & 216.1 & 206.1 & 314.0 & 306.1 & 284.1 & 371.4 & 369.2 & 362.7 & 467.2 & 461.7 & 445.8 \\
\hline $1 / n$ & 5 & 189.2 & 168.3 & 116.4 & 339.6 & 302.7 & 212.3 & 298.5 & 284.6 & 250.6 & 450.6 & 422.2 & 353.6 & 454.6 & 444.6 & 418.9 & 609.8 & 587.5 & 532.4 \\
\hline $1 / \mathrm{n}$ & 9 & 187.9 & 167.5 & & 337.2 & 301.3 & & 297.0 & 283.5 & & 448.0 & 420.3 & & 452.9 & 443.2 & & 607.0 & & 531.5 \\
\hline Sure Bet & 3 & 116.0 & 109.6 & 90.9 & 209.3 & 197.8 & 164.7 & 219.6 & 216.1 & 206.1 & 314.0 & 306.1 & 284.1 & 371.4 & 369.2 & 362 & 467.2 & 461.7 & 445.8 \\
\hline Sure Bet & 5 & 144.3 & 134.8 & 108.0 & 259.4 & 242.5 & 196.1 & 249.2 & 243.5 & 227.6 & 365.3 & 353.1 & 319.7 & 402.0 & 398.2 & 387.3 & 519.9 & 510.8 & 485.7 \\
\hline Sure Bet & 9 & 103.1 & 100.0 & 90.4 & 185.5 & 179.9 & 163.2 & 204.9 & 203.4 & 98.5 & 287.9 & 284.3 & 273.3 & 355.8 & 354.8 & 351.9 & 439.4 & 437.0 & 429.5 \\
\hline Conservative & 3 & 132.0 & 122.5 & 95.2 & 238.5 & 221.0 & 173.7 & 237.2 & 231.7 & 216.4 & 345.1 & 332.6 & 299.6 & 390.0 & 386.3 & & 499.8 & 490.8 & 466.0 \\
\hline Conservative & 5 or 9 & 144.3 & 134.8 & .0 & 259.4 & 242.5 & & 249.2 & 243.5 & & 365.3 & 353.1 & & 402.0 & 398.2 & & 519.9 & 510.8 & 485.7 \\
\hline Moderate & 3 & 166.4 & 146.2 & $\begin{array}{l}93.8 \\
\end{array}$ & 301.1 & 264.2 & 177.5 & 276.3 & 263.3 & 232.2 & 413.3 & 385.5 & 320.8 & 432.2 & 423.0 & 399.7 & 573.0 & 551.4 & 499.4 \\
\hline Moderate & 5 or 9 & & 168.3 & & & 302.7 & & 298.5 & 284.6 & & 450.6 & 422.2 & & 454.6 & 444.6 & & 605 & 587.5 & 532.4 \\
\hline Aggressive & 3 & 206.7 & 168.8 & 82.8 & 374.9 & 305.6 & 169.3 & 323.5 & 297.3 & 243.5 & 495.3 & 440.6 & 333.0 & 484.6 & 464.6 & 420.7 & 662.5 & 617.8 & 525.4 \\
\hline Aggressive & 5 or 9 & 245.7 & 204.8 & 117.5 & 440.5 & 368.3 & .9 & 361.7 & 332.2 & & 558.9 & 500.7 & & 523.3 & 500.5 & & 725 & 677.5 & 574.2 \\
\hline Life Cycle & 3 & 157.5 & 141.4 & $\begin{array}{l}99.7 \\
9\end{array}$ & 284.8 & 255.3 & 183.8 & 265.6 & 255.3 & 230.0 & 394.9 & 372.7 & 319.5 & 420.4 & 413.2 & 394.6 & 552.8 & 535.8 & 493.5 \\
\hline Life Cycle & 5 or 9 & 177.3 & 160.7 & 118.3 & 318.3 & 288.8 & 214.8 & 285.0 & 274.1 & 246.5 & 427.5 & 404.9 & 348.9 & 439.9 & 432.2 & 411.8 & 585.1 & 567.6 & 523.0 \\
\hline
\end{tabular}

16 Years of Education

\begin{tabular}{|c|c|c|c|c|c|c|c|c|c|c|c|c|c|c|c|c|c|c|c|}
\hline \multirow[b]{3}{*}{ Strategy } & \multirow[b]{3}{*}{ Choices } & \multicolumn{6}{|c|}{$\$ 0$ in Outside Wealth } & \multicolumn{6}{|c|}{$\$ 100 \mathrm{~K}$ in Outside Wealth } & \multicolumn{6}{|c|}{$\$ 250 \mathrm{~K}$ in Outside Wealth } \\
\hline & & \multicolumn{3}{|c|}{$5 \%$ Contribution Rate } & \multirow{2}{*}{\multicolumn{3}{|c|}{$\begin{array}{c}\text { 9\% Contribution Rate } \\
\gamma=1.1 \quad \gamma=2.0 \quad \gamma=5.0\end{array}$}} & \multirow{2}{*}{\multicolumn{3}{|c|}{$5 \%$ Contribution Rate }} & \multirow{2}{*}{\multicolumn{3}{|c|}{ 9\% Contribution Rate }} & \multicolumn{3}{|c|}{$5 \%$ Contribution Rate } & \multirow{2}{*}{\multicolumn{3}{|c|}{$9 \%$ Contribution Rate }} \\
\hline & & $y=1.1$ & $y=2.0$ & $y=5.0$ & & & & $y=1.1$ & & $y=5.0$ & & & & $\gamma=1.1$ & $y=2.0$ & $y=5.0$ & $y=1.1$ & & \\
\hline $1 / \mathrm{n}$ & 3 & 142.8 & 135.6 & 114.5 & 256.4 & 243.5 & 206.2 & 246.6 & 242.2 & 229.8 & 360.9 & 351.6 & 325.2 & 398.6 & 395.8 & 387.4 & 514.3 & $\overline{507.6}$ & 488.1 \\
\hline $1 / \mathrm{n}$ & 5 & 226.0 & 202.9 & 142.6 & 409.2 & 367.6 & 264.7 & 335.1 & 319.0 & 279.0 & 520.0 & 486.6 & 405.5 & 491.6 & 479.6 & 449.2 & 679.7 & 652.9 & 586.4 \\
\hline $1 / \mathrm{n}$ & 9 & 224.4 & 201.9 & 143.1 & 406.3 & 365.8 & 265.2 & 333.3 & 317.6 & 278.6 & 516.8 & 484.3 & 405.1 & 489.6 & 478.0 & 448.3 & 676.3 & 650.2 & 585.4 \\
\hline Sure Bet & 3 & 142.8 & 135.6 & 114.5 & 256.4 & 243.5 & 206.2 & 246.6 & 242.2 & 229.8 & 360.9 & 351.6 & 325.2 & 398.6 & 395.8 & 387.4 & 514.3 & 507.6 & 488.1 \\
\hline Sure Bet & 5 & 174.3 & 163.8 & 133.4 & 315.4 & 296.3 & 243.2 & 279.2 & 272.4 & 253.5 & 421.2 & 406.7 & 366.8 & 432.2 & 427.5 & 414.2 & 576.1 & 565.0 & 534.2 \\
\hline Sure Bet & 9 & 126.4 & 122.9 & 112.2 & 228.3 & 222.1 & 202.8 & 228.3 & 226.3 & 220.3 & 330.7 & 326.3 & 313.0 & 379.2 & 378.0 & 374.2 & 482.4 & 479.3 & 469.9 \\
\hline Conservative & 3 & 162.1 & 151.0 & 120.6 & 290.6 & 271.0 & 217.0 & 267.4 & 260.4 & 241.4 & 396.9 & 382.4 & 342.8 & 420.6 & 415.8 & 402.5 & 552.0 & 541.1 & 510.9 \\
\hline Conservative & 5 or 9 & 174.3 & 163.8 & 133.4 & 315.4 & 296.3 & 243.2 & 279.2 & 272.4 & 253.5 & 421.2 & 406.7 & 366.8 & 432.2 & 427.5 & 414.2 & 576.1 & 565.0 & 534.2 \\
\hline Moderate & 3 & 202.9 & 179.4 & 122.9 & 363.6 & 322.0 & 221.7 & 313.0 & 296.9 & 258.7 & 475.5 & 443.0 & 365.8 & 469.8 & 458.0 & 428.6 & 635.6 & 609.9 & 547.1 \\
\hline Moderate & 5 or 9 & 226.0 & 202.9 & 142.6 & 409.2 & 367.6 & 264.7 & 335.1 & 319.0 & 279.0 & 520.0 & 486.6 & 405.5 & 491.6 & 479.6 & 449.2 & 679.7 & 652.9 & 586.4 \\
\hline Aggressive & 3 & 250.6 & 206.7 & 116.3 & 449.2 & 371.0 & 211.2 & 367.8 & 335.6 & 270.3 & 569.0 & 505.6 & 377.6 & 530.3 & 505.1 & 450.9 & 736.9 & 684.3 & 574.2 \\
\hline Aggressive & 5 or 9 & 290.6 & 245.5 & 141.0 & 526.8 & 445.5 & 270.5 & 406.1 & 372.4 & 300.1 & 644.8 & 577.0 & 434.4 & 568.2 & 541.7 & 482.5 & 811.9 & 755.1 & 632.1 \\
\hline Life Cycle & 3 & 191.6 & 173.2 & 127.5 & 343.1 & 310.5 & 229.5 & 299.8 & 287.3 & 256.4 & 452.7 & 427.4 & 365.0 & 455.2 & 446.2 & 422.9 & 610.9 & 591.0 & 540.8 \\
\hline Life Cycle & 5 or 9 & 211.4 & 193.2 & 145.3 & 382.7 & 349.8 & 266.3 & 318.9 & 306.3 & 274.3 & 491.6 & 465.4 & 399.7 & 474.1 & 464.9 & 440.9 & 649.4 & 628.6 & 575.4 \\
\hline
\end{tabular}


Table 1B: Simulations of Certainty Equivalent Wealth Accumulation

Expressed as a Fraction of Certainty Equivalent Wealth Under Aggressive Investment Strategy 11 Years of Education

\begin{tabular}{|c|c|c|c|c|c|c|c|c|c|c|c|c|c|c|c|c|c|c|c|}
\hline \multirow[b]{3}{*}{ Strategy } & \multirow[b]{3}{*}{ Choices } & \multicolumn{6}{|c|}{$\$ 0$ in Outside Wealth } & \multicolumn{6}{|c|}{$\$ 100 \mathrm{~K}$ in Outside Wealth } & \multicolumn{6}{|c|}{$\$ 250 \mathrm{~K}$ in Outside Wealth } \\
\hline & & \multirow{2}{*}{\multicolumn{3}{|c|}{$\begin{array}{c}\text { 5\% Contribution Rate } \\
\gamma=20\end{array}$}} & \multirow{2}{*}{\multicolumn{3}{|c|}{ 9\% Contribution Rate }} & \multirow{2}{*}{\multicolumn{3}{|c|}{ 5\% Contribution Rate }} & \multicolumn{3}{|c|}{ 9\% Contribution Rate } & \multicolumn{3}{|c|}{$5 \%$ Contribution Rate } & \multirow{2}{*}{\multicolumn{3}{|c|}{ 9\% Contribution Rate }} \\
\hline & & & & & $y=1.1$ & & & & & & $\gamma=1.1$ & $\gamma=2.0$ & $y=5.0$ & $\gamma=1.1$ & $\gamma=2.0$ & $y=5.0$ & $\gamma=1.1$ & & \\
\hline $1 / \mathrm{n}$ & 3 & 0.54 & 0.64 & 1.04 & 0.54 & 0.63 & 1.03 & 0.69 & 0.74 & 0.84 & 0.64 & 0.70 & 0.84 & 0.79 & 0.81 & 0.87 & 0.72 & 0.76 & 0.85 \\
\hline $1 / n$ & 5 & 0.76 & 0.82 & 1.01 & 0.76 & 0.82 & 1.00 & 0.83 & 0.86 & 0.93 & 0.81 & 0.84 & 0.93 & 0.88 & 0.90 & 0.93 & 0.85 & 0.87 & 0.93 \\
\hline $1 / n$ & 9 & 0.76 & 0.81 & 1.02 & 0.76 & 0.81 & 1.00 & 0.83 & 0.86 & 0.93 & 0.80 & 0.84 & 0.93 & 0.88 & 0.89 & 0.93 & 0.85 & 0.87 & 0.93 \\
\hline Sure Bet & 3 & 0.54 & 0.64 & 1.04 & 0.54 & 0.63 & 1.03 & 0.69 & 0.74 & 0.84 & 0.64 & 0.70 & 0.84 & 0.79 & 0.81 & 0.87 & 0.72 & 0.76 & 0.85 \\
\hline Sure Bet & 5 & 0.57 & 0.65 & 0.95 & 0.58 & 0.65 & 0.93 & 0.70 & 0.74 & 0.84 & 0.66 & 0.71 & 0.84 & 0.79 & 0.81 & 0.87 & 0.73 & 0.77 & 0.85 \\
\hline Sure Bet & 9 & 0.40 & 0.47 & 0.79 & 0.40 & 0.47 & 0.77 & 0.58 & 0.63 & 0.74 & 0.53 & 0.58 & 0.72 & 0.71 & 0.73 & 0.80 & 0.63 & 0.67 & 0.76 \\
\hline Conservative & 3 & 0.62 & 0.71 & 1.09 & 0.62 & 0.71 & 1.09 & 0.74 & 0.79 & 0.88 & 0.70 & 0.76 & 0.89 & 0.82 & 0.84 & 0.90 & 0.77 & 0.80 & 0.89 \\
\hline Conservative & 5 or 9 & 0.57 & 0.65 & 0.95 & 0.58 & 0.65 & 0.93 & 0.70 & 0.74 & 0.84 & 0.66 & 0.71 & 0.84 & 0.79 & 0.81 & 0.87 & 0.73 & 0.77 & 0.85 \\
\hline Moderate & 3 & 0.80 & 0.86 & 1.09 & 0.79 & 0.86 & 1.09 & 0.86 & 0.89 & 0.95 & 0.84 & 0.87 & 0.96 & 0.90 & 0.92 & 0.95 & 0.87 & 0.90 & 0.95 \\
\hline Moderate & 5 or 9 & 0.76 & 0.82 & 1.01 & 0.76 & 0.82 & 1.00 & 0.83 & 0.86 & 0.93 & 0.81 & 0.84 & 0.93 & 0.88 & 0.90 & 0.93 & 0.85 & 0.87 & 0.93 \\
\hline Aggressive & 3 & 1.00 & 1.00 & 1.00 & 1.00 & 1.00 & 1.00 & 1.00 & 1.00 & 1.00 & 1.00 & 1.00 & 1.00 & 1.00 & 1.00 & 1.00 & 1.00 & 1.00 & 1.00 \\
\hline Aggressive & 5 or 9 & 1.00 & 1.00 & 1.00 & 1.00 & 1.00 & 1.00 & 1.00 & 1.00 & 1.00 & 1.00 & 1.00 & 1.00 & 1.00 & 1.00 & 1.00 & 1.00 & 1.00 & 1.00 \\
\hline Life Cycle & 3 & 0.75 & 0.83 & 1.15 & 0.75 & 0.83 & 1.14 & 0.83 & 0.86 & 0.94 & 0.80 & 0.85 & 0.95 & 0.88 & 0.90 & 0.94 & 0.84 & 0.87 & 0.94 \\
\hline Life Cycle & 5 or 9 & 0.71 & 0.78 & 1.04 & 0.72 & 0.78 & 1.02 & 0.80 & 0.83 & 0.91 & 0.77 & 0.81 & 0.92 & 0.85 & 0.87 & 0.92 & 0.82 & 0.85 & 0.91 \\
\hline
\end{tabular}

14 Years of Education

\begin{tabular}{|c|c|c|c|c|c|c|c|c|c|c|c|c|c|c|c|c|c|c|c|}
\hline \multirow[b]{3}{*}{ Strategy } & \multirow[b]{3}{*}{ Choices } & \multicolumn{6}{|c|}{$\$ 0$ in Outside Wealth } & \multicolumn{6}{|c|}{$\$ 100 \mathrm{~K}$ in Outside Wealth } & \multicolumn{6}{|c|}{$\$ 250 \mathrm{~K}$ in Outside Wealth } \\
\hline & & \multicolumn{3}{|c|}{$5 \%$ Contribution Rate } & \multirow{2}{*}{\multicolumn{3}{|c|}{ 9\% Contribution Rate }} & \multirow{2}{*}{\multicolumn{3}{|c|}{$5 \%$ Contribution Rate }} & \multicolumn{3}{|c|}{ 9\% Contribution Rate } & \multicolumn{3}{|c|}{ 5\% Contribution Rate } & \multicolumn{3}{|c|}{ 9\% Contribution Rate } \\
\hline & & $y=1.1$ & $\gamma=2.0$ & $y=5.0$ & $\gamma=1.1$ & & & $\gamma=1.1$ & & $\gamma=5.0$ & $\gamma=1.1$ & $\gamma=2.0$ & $\gamma=5.0$ & $y=1.1$ & $\gamma=2.0$ & $\gamma=5.0$ & $\gamma=1.1$ & $\gamma=2.0$ & $\gamma=5.0$ \\
\hline $1 / \mathrm{n}$ & 3 & 0.56 & 0.65 & 1.10 & 0.56 & 0.65 & 0.97 & 0.68 & 0.73 & 0.85 & 0.63 & 0.69 & 0.85 & 0.77 & 0.79 & 0.86 & 0.71 & 0.75 & 0.85 \\
\hline $1 / n$ & 5 & 0.77 & 0.82 & 0.99 & 0.77 & 0.82 & 0.99 & 0.83 & 0.86 & 0.93 & 0.81 & 0.84 & 0.93 & 0.87 & 0.89 & 0.93 & 0.84 & 0.87 & 0.93 \\
\hline $1 / n$ & 9 & 0.76 & 0.82 & 0.99 & 0.77 & 0.82 & 0.99 & 0.82 & 0.85 & 0.93 & 0.80 & 0.84 & 0.93 & 0.87 & 0.89 & 0.93 & 0.84 & 0.86 & 0.93 \\
\hline Sure Bet & 3 & 0.56 & 0.65 & 1.10 & 0.56 & 0.65 & 0.97 & 0.68 & 0.73 & 0.85 & 0.63 & 0.69 & 0.85 & 0.77 & 0.79 & 0.86 & 0.71 & 0.75 & 0.85 \\
\hline Sure Bet & 5 & 0.59 & 0.66 & 0.92 & 0.59 & 0.66 & 0.91 & 0.69 & 0.73 & 0.84 & 0.65 & 0.71 & 0.84 & 0.77 & 0.80 & 0.86 & 0.72 & 0.75 & 0.85 \\
\hline Sure Bet & 9 & 0.42 & 0.49 & 0.77 & 0.42 & 0.49 & 0.76 & 0.57 & 0.61 & 0.74 & 0.52 & 0.57 & 0.72 & 0.68 & 0.71 & 0.78 & 0.61 & 0.65 & 0.75 \\
\hline Conservative & 3 & 0.64 & 0.73 & 1.15 & 0.64 & 0.72 & 1.03 & 0.73 & 0.78 & 0.89 & 0.70 & 0.75 & 0.90 & 0.80 & 0.83 & 0.89 & 0.75 & 0.79 & 0.89 \\
\hline Conservative & 5 or 9 & 0.59 & 0.66 & 0.92 & 0.59 & 0.66 & 0.91 & 0.69 & 0.73 & 0.84 & 0.65 & 0.71 & 0.84 & 0.77 & 0.80 & 0.86 & 0.72 & 0.75 & 0.85 \\
\hline Moderate & 3 & 0.80 & 0.87 & 1.13 & 0.80 & 0.86 & 1.05 & 0.85 & 0.89 & 0.95 & 0.83 & 0.87 & 0.96 & 0.89 & 0.91 & 0.95 & 0.86 & 0.89 & 0.95 \\
\hline Moderate & 5 or 9 & 0.77 & 0.82 & 0.99 & 0.77 & 0.82 & 0.99 & 0.83 & 0.86 & 0.93 & 0.81 & 0.84 & 0.93 & 0.87 & 0.89 & 0.93 & 0.84 & 0.87 & 0.93 \\
\hline Aggressive & 3 & 1.00 & 1.00 & 1.00 & 1.00 & 1.00 & 1.00 & 1.00 & 1.00 & 1.00 & 1.00 & 1.00 & 1.00 & 1.00 & 1.00 & 1.00 & 1.00 & 1.00 & 1.00 \\
\hline Aggressive & 5 or 9 & 1.00 & 1.00 & 1.00 & 1.00 & 1.00 & 1.00 & 1.00 & 1.00 & 1.00 & 1.00 & 1.00 & 1.00 & 1.00 & 1.00 & 1.00 & 1.00 & 1.00 & 1.00 \\
\hline Life Cycle & 3 & 0.76 & 0.84 & 1.20 & 0.76 & 0.84 & 1.09 & 0.82 & 0.86 & 0.94 & 0.80 & 0.85 & 0.96 & 0.87 & 0.89 & 0.94 & 0.83 & 0.87 & 0.94 \\
\hline Life Cycle & 5 or 9 & 0.72 & 0.78 & 1.01 & 0.72 & 0.78 & 1.00 & 0.79 & 0.82 & 0.91 & 0.76 & 0.81 & 0.92 & 0.84 & 0.86 & 0.92 & 0.81 & 0.84 & 0.91 \\
\hline
\end{tabular}

16 Years of Education

\begin{tabular}{|c|c|c|c|c|c|c|c|c|c|c|c|c|c|c|c|c|c|c|c|}
\hline \multirow[b]{3}{*}{ Strategy } & \multirow[b]{3}{*}{ Choices } & \multicolumn{6}{|c|}{$\$ 0$ in Outside Wealth } & \multicolumn{6}{|c|}{$\$ 100 \mathrm{~K}$ in Outside Wealth } & \multicolumn{6}{|c|}{ \$250K in Outside Wealth } \\
\hline & & \multirow{2}{*}{\multicolumn{3}{|c|}{$5 \%$ Contribution Rate }} & \multicolumn{3}{|c|}{$9 \%$ Contribution Rate } & \multicolumn{3}{|c|}{$5 \%$ Contribution Rate } & \multicolumn{3}{|c|}{$9 \%$ Contribution Rate } & \multicolumn{3}{|c|}{$5 \%$ Contribution Rate } & \multicolumn{3}{|c|}{$9 \%$ Contribution Rate } \\
\hline & & $\gamma=1.1$ & & $\gamma=5.0$ & $\gamma=1.1$ & $\gamma=2.0$ & $\gamma=5.0$ & $\gamma=1.1$ & $\gamma=2.0$ & $\gamma=5.0$ & $\gamma=1.1$ & $\gamma=2.0$ & $\gamma=5.0$ & $\gamma=1.1$ & $y=2.0$ & $\gamma=5.0$ & $\gamma=1.1$ & $\underline{\gamma=2.0}$ & $\gamma=5.0$ \\
\hline $1 / \mathrm{n}$ & 3 & 0.57 & 0.66 & 0.98 & 0.57 & 0.66 & 0.98 & 0.67 & 0.72 & 0.85 & 0.63 & 0.70 & 0.86 & 0.75 & 0.78 & 0.86 & 0.70 & 0.74 & 0.85 \\
\hline $1 / n$ & 5 & 0.78 & 0.83 & 1.01 & 0.78 & 0.83 & 0.98 & 0.83 & 0.86 & 0.93 & 0.81 & 0.84 & 0.93 & 0.87 & 0.89 & 0.93 & 0.84 & 0.86 & 0.93 \\
\hline $1 / \mathrm{n}$ & 9 & 0.77 & 0.82 & 1.02 & 0.77 & 0.82 & 0.98 & 0.82 & 0.85 & 0.93 & 0.80 & 0.84 & 0.93 & 0.86 & 0.88 & 0.93 & 0.83 & 0.86 & 0.93 \\
\hline Sure Bet & 3 & 0.57 & 0.66 & 0.98 & 0.57 & 0.66 & 0.98 & 0.67 & 0.72 & 0.85 & 0.63 & 0.70 & 0.86 & 0.75 & 0.78 & 0.86 & 0.70 & 0.74 & 0.85 \\
\hline Sure Bet & 5 & 0.60 & 0.67 & 0.95 & 0.60 & 0.66 & 0.90 & 0.69 & 0.73 & 0.84 & 0.65 & 0.70 & 0.84 & 0.76 & 0.79 & 0.86 & 0.71 & 0.75 & 0.85 \\
\hline Sure Bet & 9 & 0.43 & 0.50 & 0.80 & 0.43 & 0.50 & 0.75 & 0.56 & 0.61 & 0.73 & 0.51 & 0.57 & 0.72 & 0.67 & 0.70 & 0.78 & 0.59 & 0.63 & 0.74 \\
\hline Conservative & 3 & 0.65 & 0.73 & 1.04 & 0.65 & 0.73 & 1.03 & 0.73 & 0.78 & 0.89 & 0.70 & 0.76 & 0.91 & 0.79 & 0.82 & 0.89 & 0.75 & 0.79 & 0.89 \\
\hline Conservative & 5 or 9 & 0.60 & 0.67 & 0.95 & 0.60 & 0.66 & 0.90 & 0.69 & 0.73 & 0.84 & 0.65 & 0.70 & 0.84 & 0.76 & 0.79 & 0.86 & 0.71 & 0.75 & 0.85 \\
\hline Moderate & 3 & 0.81 & 0.87 & 1.06 & 0.81 & 0.87 & 1.05 & 0.85 & 0.88 & 0.96 & 0.84 & 0.88 & 0.97 & 0.89 & 0.91 & 0.95 & 0.86 & 0.89 & 0.95 \\
\hline Moderate & 5 or 9 & 0.78 & 0.83 & 1.01 & 0.78 & 0.83 & 0.98 & 0.83 & 0.86 & 0.93 & 0.81 & 0.84 & 0.93 & 0.87 & 0.89 & 0.93 & 0.84 & 0.86 & 0.93 \\
\hline Aggressive & 3 & 1.00 & 1.00 & 1.00 & 1.00 & 1.00 & 1.00 & 1.00 & 1.00 & 1.00 & 1.00 & 1.00 & 1.00 & 1.00 & 1.00 & 1.00 & 1.00 & 1.00 & 1.00 \\
\hline Aggressive & 5 or 9 & 1.00 & 1.00 & 1.00 & 1.00 & 1.00 & 1.00 & 1.00 & 1.00 & 1.00 & 1.00 & 1.00 & 1.00 & 1.00 & 1.00 & 1.00 & 1.00 & 1.00 & 1.00 \\
\hline Life Cycle & 3 & 0.76 & 0.84 & 1.10 & 0.76 & 0.84 & 1.09 & 0.82 & 0.86 & 0.95 & 0.80 & 0.85 & 0.97 & 0.86 & 0.88 & 0.94 & 0.83 & 0.86 & 0.94 \\
\hline Life Cycle & 5 or 9 & 0.73 & 0.79 & 1.03 & 0.73 & 0.79 & 0.98 & 0.79 & 0.82 & 0.91 & 0.76 & 0.81 & 0.92 & 0.83 & 0.86 & 0.91 & 0.80 & 0.83 & 0.91 \\
\hline
\end{tabular}


Figure 1A: Simulations of Retirement Wealth Accumulation:

11 years of Education, Contribution Rate of $5 \%$

Endpoints of vertical line depict 0.05- and 0.95-quantiles of retirement wealth

Top of black box depicts mean, Bottom of black box depicts median

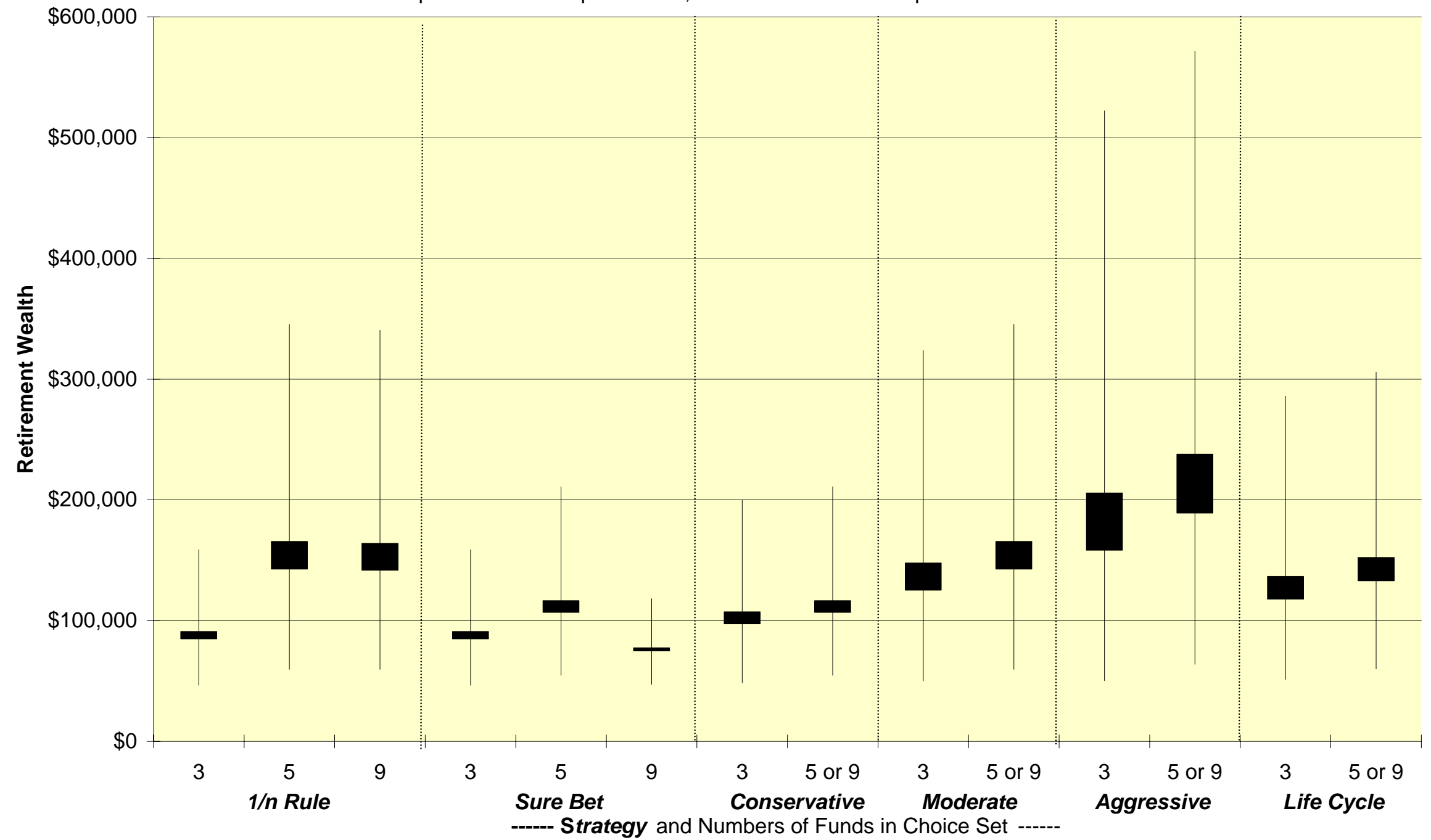


Figure 1B: Simulations of Retirement Wealth Accumulation:

11 years of Education, Contribution Rate of $9 \%$

Endpoints of vertical line depict 0.05- and 0.95-quantiles of retirement wealth

Top of black box depicts mean, Bottom of black box depicts median

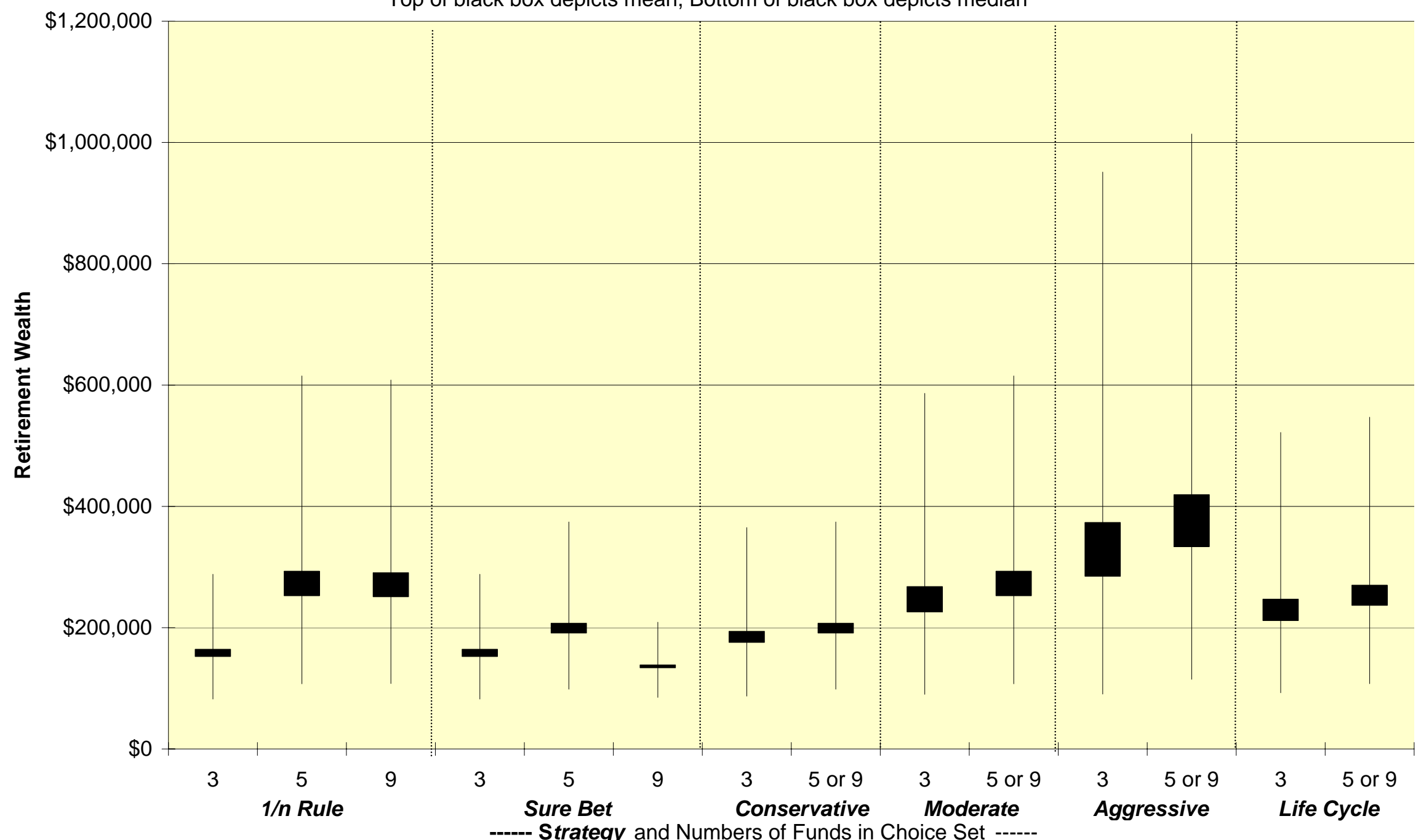


Figure 1C: Simulations of Retirement Wealth Accumulation:

16 years of Education, Contribution Rate of $5 \%$

Endpoints of vertical line depict 0.05- and 0.95-quantiles of retirement wealth

Top of black box depicts mean, Bottom of black box depicts median

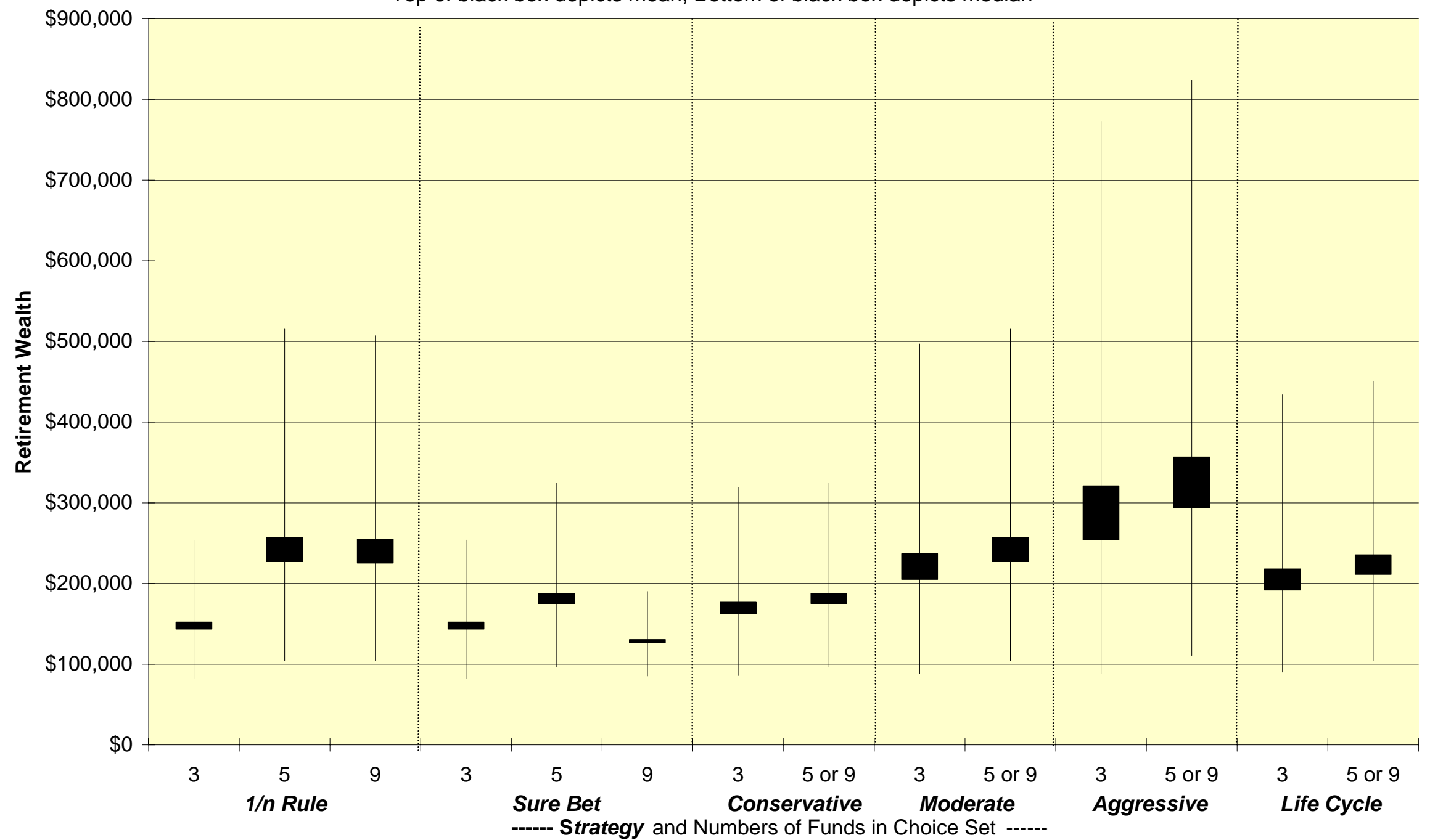


Figure 2A: Simulations of Certainty Equivalent Wealth Accumulation 11 years of Education, $5 \%$ Contribution Rate, $\$ 0$ Outside Wealth

Endpoints of vertical line depict certainty equivalent wealth for $\gamma=1.1$ (top) and $\gamma=5$ (bottom)

Horizontal line depicts $\gamma=2$

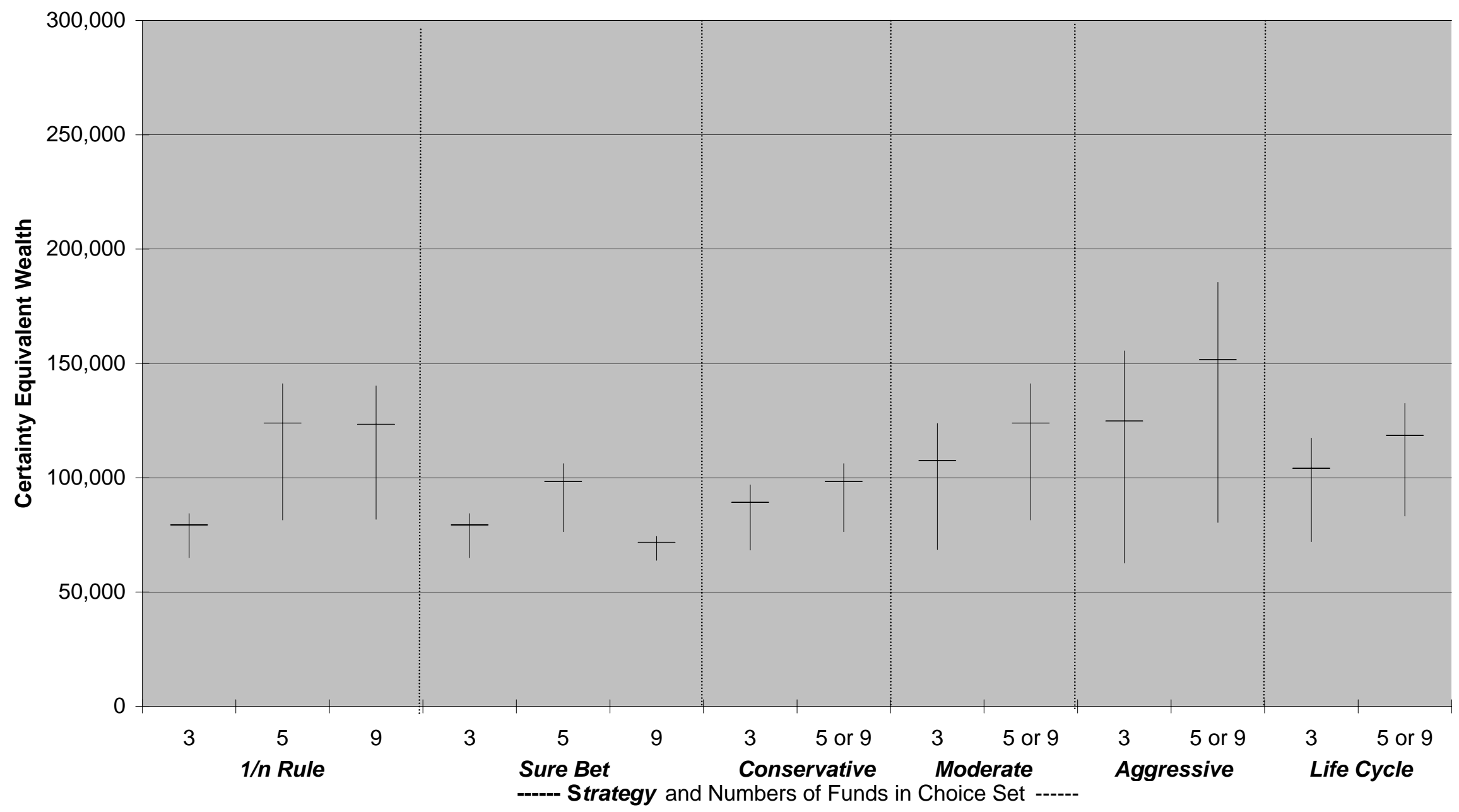


Figure 2B: Simulations of Certainty Equivalent Wealth Accumulation

11 years of Education, 5\% Contribution Rate, $\$ 100 \mathrm{k}$ Outside Wealth

Endpoints of vertical line depict certainty equivalent wealth for $\gamma=1.1$ (top) and $\gamma=5$ (bottom)

Horizontal line depicts $\gamma=2$

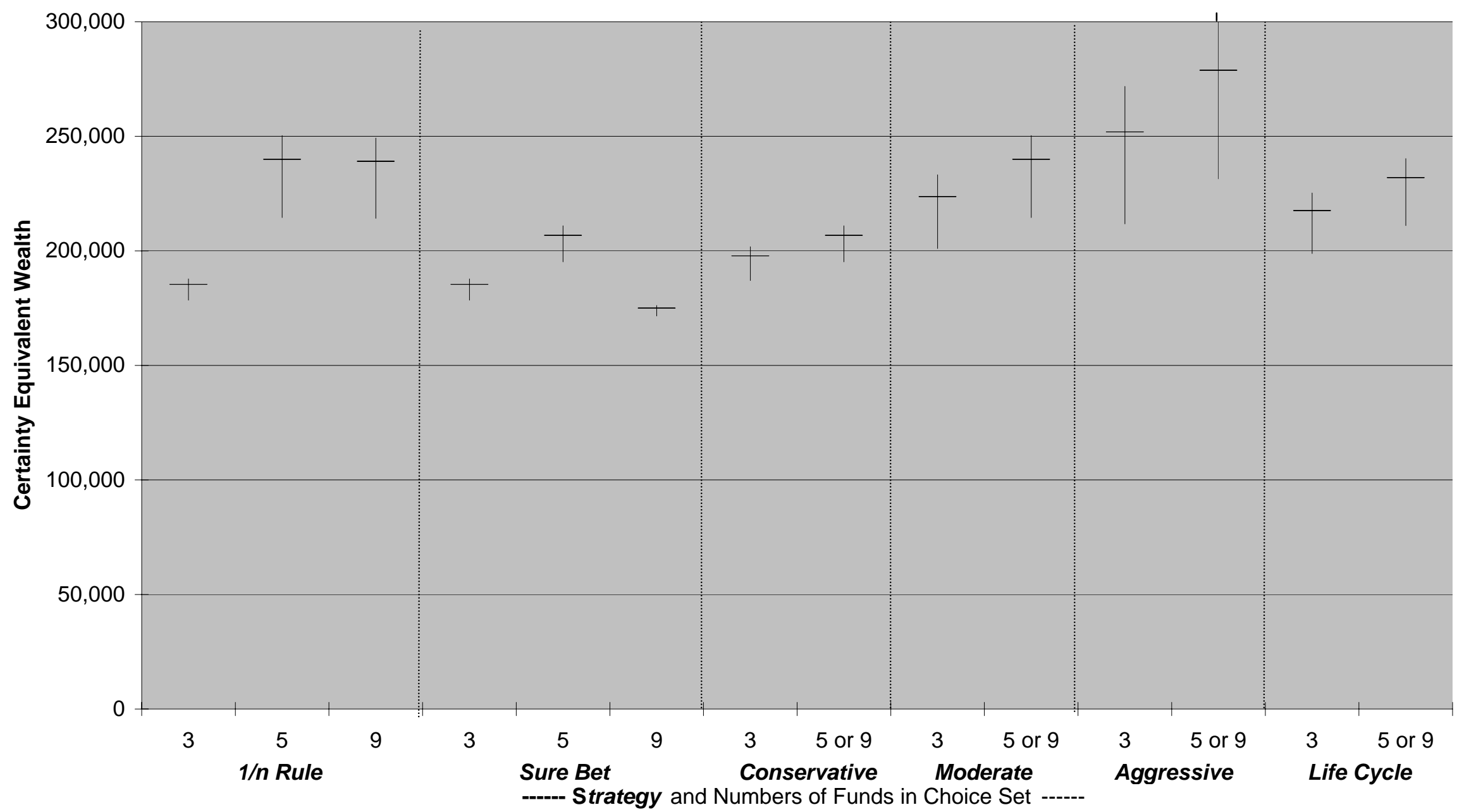

